\title{
ESPACIOS PÚBLICOS: ESTUDIO DEL DISTRITO DE SANTIAGO DE SURCO EN LIMA, PERÚ ${ }^{1}$
}

\author{
Ana Sabogal Dunin Borkowski \\ María Alejandra Cuentas Romero \\ Tarik Tavera Medina \\ Fresia Vargas Chunga \\ Pontificia Universidad Católica del Perú
}

\begin{abstract}
Resumen: El presente artículo busca mostrar los vacíos que actualmente posee la normativa legal de Lima Metropolitana y la gestión municipal referente a los espacios públicos. Se toma como caso de estudio el distrito de Santiago deSurco por su heterogeneidad en su composición urbana, nivel socioeconómico y el contenido en espacios públicos. En esta área de estudio se seleccionaron parques representativos de los diversos niveles económicos. En ellos se realizaron observaciones en torno a la percepción sobre calidad y su relevancia para los habitantes del distrito. A pesar de contar con parques con superficies considerables y donde se llevan a cabo diversas actividades, estos no están bajo un sistema de gestión legal apropiado para asegurar su mantenimiento y mejora para el futuro, y menos aún para contribuir a la calidad de vida de los vecinos. A lo largo del artículo se desarrolla un contraste entre los hallazgos de la literatura y la percepción de los investigadores en relación con el estado actual de los parques estudiados como espacios públicos.
\end{abstract}

Palabras clave: Espacios públicos. Parques. Santiago de Surco. Normativa legal urbana.

1 Una versión preliminar de este artículo fue presentada en la V Mesa de Reflexión Ambiental: Kawsaypacha 2016, espacio de discusión académica organizado por el INTEPUCP (octubre 2016). 


\title{
Public Spaces: Study in the District of Santiago de Surco
}

\begin{abstract}
The present article seeks to show the gaps that currently have the legal regulations of Lima Metropolitan and the management concerning public spaces. The district of Santiago de Surco is taken as a case study by its heterogeneity in its urban composition, socioeconomic level and content in public spaces. In this area of study, according to criteria previously discussed, representative parks of different economic levels were selected as object of study. In them observations were made on the perception about quality and its relevance for the inhabitants of the district. Despite the fact that there are large parks with a number of activities, they are not under an appropriate legal management system to ensure their maintenance and improvement for the future, and even less to contribute to the quality of life of the neighbors. Throughout the article a contrast between the findings of the literature and the perception of the researchers in relation to the current state of the parks studied as public spaces is developed.
\end{abstract}

Keywords: Public Spaces. Parks. Santiago de Surco. Urban Legal Regulations.

\section{Ana Sabogal Dunin Borkowski:}

Doctora en Ciencias Naturales por la Universidad Técnica de Berlín. Magíster en Desarrollo Agrario Internacional por la misma universidad. Ingeniera Agrónoma de la Universidad Nacional Agraria La Molina. Docente del Departamento de Humanidades, Sección Geografía y Medio Ambiente de la Pontificia Universidad Católica del Perú (PUCP). Ha sido directora de Investigación e Información en el Ministerio del Ambiente.

Doctora en Ciencias Naturales y magíster en Desarrollo Agrario Internacional por la Universidad Técnica de Berlín. Profesora Asociada del Departamento de Humanidades, Sección Geografía y Medio Ambiente, investigadora del Centro de Investigación en Geografía Aplicada (CIGA), coordinadora del grupo Bosques y Reforestación y miembro del Consejo Directivo del INTE-PUCP, en la de la Pontifica Universidad Católica del Perú (PUCP). Especialista en Ecología Vegetal.

Correo electrónico: asabogal@pucp.pe 
María Alejandra Cuentas Romero: Licenciada en Geografía y Medio Ambiente por la PUCP Asistente de investigación en la PUCP. Miembro del grupo Bosques y Reforestación del INTE-PUCP.

Correo: alejandra.cuentasr@pucp.edu.pe

Tarik Tavera Medina: Estudiante del séptimo ciclo de la especialidad de Geografía y Medio Ambiente de la PUCP. Ha ganado los premios de investigación académica de la facultad de Estudios Generales Letras y el programa de Apoyo a la Iniciación a la Investigación (PAIN2016) de esta misma universidad. Actualmente apoya en la labor de la investigación del grupo Bosques y Reforestación del INTE-PUCP

Correo electrónico: tarik.tavera@pucp.pe

Fresia Vargas Chunga: Licenciada en Geografía y Medio Ambiente por la PUCP. Asistente de investigación en la PUCP. Miembro del grupo Bosques y Reforestación del INTE-PUCP.

Correo electrónico: fvargasc@pucp.pe 



\section{Introducción}

En un contexto de crecimiento poblacional y urbanización acelerados de la ciudad de Lima, se han dejado de lado las políticas e instrumentos de gestión que se enfocan en el tratamiento de los espacios públicos. A ello se suman los altos niveles de contaminación y congestión que aparecen como una de las principales externalidades negativas de este crecimiento poblacional. Los espacios públicos, sobre todo los que poseen una gran cantidad de áreas verdes, podrían compensar o mitigar los efectos de esta problemática. Sin embargo, su número es insuficiente, su gestión es deficiente y su calidad como espacios públicos es discutible. Esto es, por un lado, resultado de una débil gobernanza y, por otro, de la ausencia de políticas públicas nacionales que guíen el actuar de las autoridades locales para lograr el desarrollo urbano sostenible.

El parque viene a ser un tipo de espacio público cuyas funciones son principalmente recreativas, y está caracterizado por la presencia de áreas verdes y en algunos casos equipamiento e infraestructura destinados a actividades deportivas y de recreación. Los parques son, por tanto, un elemento importante en la estructura urbana de una ciudad con dimensiones como las de Lima y contribuyen a la mejora de la calidad de vida de los habitantes. Si bien los servicios que pueden ofrecer estos espacios son varios, los estudios aún no los han podido cuantificar ni valorizar como lo merecen. Esto se debe a la falta de un marco legal adecuado y a una deficiente gestión pública. En este sentido, Eliseo Talancha en su texto Régimen legal de los parques ambientales en el Perú sostiene que la legislación peruana sobre los parques no está armada ni organizada, sino que aún está en un proceso de formación. Para Talancha es vital «[...] estructurar y ordenar una legislación especial que contribuya a definir los lineamientos, planes, programas y cursos de acción para desarrollar una gestión eficaz y eficiente de los parques ambientales y demás áreas verdes a favor de las presente y futuras generaciones» (2013: 28). Este autor plantea, asimismo, que «La importancia y valoración de los parques justifica contar con una legislación especial que aborde transversalmente su impacto económico, político, social, urbanístico y ambiental» (Talancha 2013: 9). 


\section{Los espacios públicos en Lima}

Lima es el resultado no planificado de una ciudad. Desde los años setenta ha sufrido una gran migración del campo a la ciudad. Actualmente cuenta con casi diez millones de habitantes y enormes problemas de contaminación del aire que repercuten en la salud de la población. Casi el 70\% de la ciudad ha sido ocupada informalmente, sin planificación previa alguna (Ludeña 2013). Aunque en los últimos años está cambiando la visión de los habitantes de Lima, aún las áreas verdes son consideradas un lujo y son escasamente valoradas por la población. Las invasiones utilizan en primer lugar los espacios destinados a las áreas verdes (Da Gama 2008); de esta manera, muchos de los espacios verdes han sido invadidos por la migración y otros no han podido prosperar por la falta de agua característica del ecosistema del desierto de Lima, lo que hace que el costo de mantenimiento de los espacios verdes sea muy elevado. Como resultado, los espacios públicos son muy pocos y muchos de estos se encuentran en un estado de abandono.

Lima tiene $2.71 \mathrm{~m}^{2}$ de áreas verdes por habitante (Romero 2017). Debido al elevado costo de mantenimiento, existe una correlación entre el poder adquisitivo de la población y el porcentaje de áreas verdes en la ciudad. Algunos distritos con mayor poder adquisitivo poseen suficientes metros cuadrados de áreas verdes por habitante $\left(\mathrm{m}^{2} / \mathrm{hab}\right.$ ), tal es el caso de San Isidro con $19.92 \mathrm{~m}^{2}$ /hab., Miraflores con $13.76 \mathrm{~m}^{2} /$ hab. y Jesús María con $9.02 \mathrm{~m}^{2} /$ hab.; mientras que otros con menos ingresos poseen muy pocos como Villa María del Triunfo con tan solo $0.34 \mathrm{~m}^{2} / \mathrm{hab}$., Breña con $0.37 \mathrm{~m}^{2}$ / hab., San Juan de Lurigancho con $0.61 \mathrm{~m}^{2} / \mathrm{hab}$. (Lima cómo vamos 2014).

En esta nueva sociedad urbana con pocos ingresos por tributos y mucha informalidad, con una gran modificación de las estructuras sociales y un elevado ascenso social, la población se encuentra enfocada en conseguir los ingresos para lograr insertarse en la sociedad y mejorar sus condiciones de vida. Es recién en la última década que el auge económico del país ha permitido iniciar un debate reciente sobre los problemas urbanos, sin

embargo, la participación de la ciudadanía en este proceso es casi nula. Las políticas públicas, por su parte, no se encuentran enfocadas ni en las áreas verdes ni menos en los espacios públicos, y la gobernabilidad se encuentra disgregada entre los ministerios, la municipalidad metropolitana y los municipios locales.

Actualmente Lima cuenta con un Observatorio Ambiental - Lima Cómo Vamos - que sistematiza la percepción de los habitantes. Los problemas ambientales principales desde la percepción ambiental de la población de Lima son: el tráfico y la falta de áreas verdes (Lima cómo vamos 2014). Entre otros problemas se menciona el suministro y la calidad del 
agua, así como la contaminación del aire. Cabe mencionar que la incidencia de enfermedades respiratorias y diarrea son aún muy elevadas, siendo para 2009 el 6\%, aunque no aparecen como problemas percibidos por la población (Liebenthal et al. 2011).

En Lima el mayor problema de contaminación del aire son las partículas en suspensión de diámetro inferior a 2.5 micras (PM2.5) y las partículas en suspensión de diámetro inferior a 10 micras (PM10). ${ }^{2}$ Estos dos tipos de partículas en suspensión se encontraron durante más del 30\% del año por encima del valor permitido, el problema es aún mayor en el centro de la ciudad (MINAM 2012). Los niveles de dióxido de azufre y óxido de nitrógeno se encuentran solo muy ligeramente por debajo del límite máximo permitido (LMP) (MINAM 2012). La concentración de material particulado de Lima es mayor que el de las ciudades de Santiago, México y Sao Paulo (World Bank Group 2009, citado por Liebenthal et al. 2011). Los costos de la elevada contaminación han sido estimados en $3.9 \%$ del Producto Bruto Interno (PBI) de 2003 (Liebenthal et al. 2011) y en 0.9\% del PBI de 2012, y en más de 6.000 muertes, sobre todo en los sectores económicos de menores recursos (MINAM 2012).

Los espacios verdes permiten la multiculturalidad y la tolerancia de las ciudades, funciones que en Lima no se pueden cumplir. Según Watson (2013), la identificación de la población con los espacios públicos posee cuatro dimensiones: ser accesibles, conectados, permeables y elegibles. La población debe poder identificarse con estos ámbitos y ello se traduce en espacios permeables, vitales, variados y elegibles por la población (Watson 2013). Los habitantes de Lima crean sus propios espacios públicos no formales e ignorados por la normatividad (Ludeña 2013). Los pocos espacios públicos formales existentes no poseen una calidad adecuada ni reconocen las costumbres y las necesidades de la población; ello conlleva a la falta de identificación de la población con los espacios públicos formales, creándose espacios públicos paralelos e informales aceptados y modificados por la población.

\section{1 Área de estudio}

El área de estudio fueron los espacios públicos del distrito de Santiago de Surco, ubicado en la zona central occidental de Lima. Como datos sobre el lugar, el distrito comprende una altitud entre 68 hasta los $400 \mathrm{msnm}$ presentes en el cerro San Francisco. Tiene una superficie de aproximadamente $44.75 \mathrm{~km}^{2}$,

2 Una mayor explicación sobre este tipo de partículas y sus efectos en la salud se pueden encontrar en la página web de la organización Ecologistas en Acción. 
mientras que su relieve es plano y cruza el Canal Río Surco, el cual nace en Santa Marta en el distrito de Ate-Vitarte y desemboca en el mar a la altura de la playa Chira, en el distrito de Chorrillos (Municipalidad de Santiago de Surco 2013). Su temperatura media en verano es de aproximadamente $23^{\circ} \mathrm{C}$, mientras que en invierno hay una temperatura media de $15^{\circ} \mathrm{C}$. La humedad promedio en verano es del 80\% y en invierno del 89\% (Municipalidad de Santiago de Surco 2013). ${ }^{3}$ Finalmente, como parte de su estructura, el distrito está dividido en nueve sectores que facilitan la administración por parte de la municipalidad y está distribuido en 3.346 manzanas (Municipalidad de Santiago de Surco 2013).

\subsection{Materiales y métodos}

Se definieron en primer lugar los espacios públicos con la modalidad de parques en el distrito. A partir de esto se seleccionaron parques en cada sector según ciertos criterios: la superficie del parque, la frecuencia de visitantes y su ubicación en el sector. Es así que se optaron por los siguientes parques: Parque Casuarinas, Parque La Alborada, Parque del Leonismo, Parque Marco Schenone, Parque Perú y Parque de La Amistad.

Los métodos de trabajo fueron principalmente dos. El primer método consistió en el mapeo de los parques trabajados en esta primera etapa de la investigación identificando en estos el área, conexiones viales y observar de manera general su composición entre áreas verdes e infraestructura. Esto se trabajó con las herramientas cartográficas ArcGis y Google Earth. El segundo consistió en la observación del estado de los espacios públicos (parques) seleccionados en cuanto a infraestructura, vegetación, equipamiento y servicios que ofrecen a los ciudadanos. Dichos criterios se trabajaron a partir de una ficha de observación (ver tabla 1) para evaluar calidad, la cual fue elaborada por los autores. 
ESPACIOS PÚBlicos: ESTUdio EN EL DISTRITO DE SANTIAGo DE SURCO En Lima, Perú / Ana Sabogal y otros

Figura 1.

Ubicación del distrito de Santiago de Surco

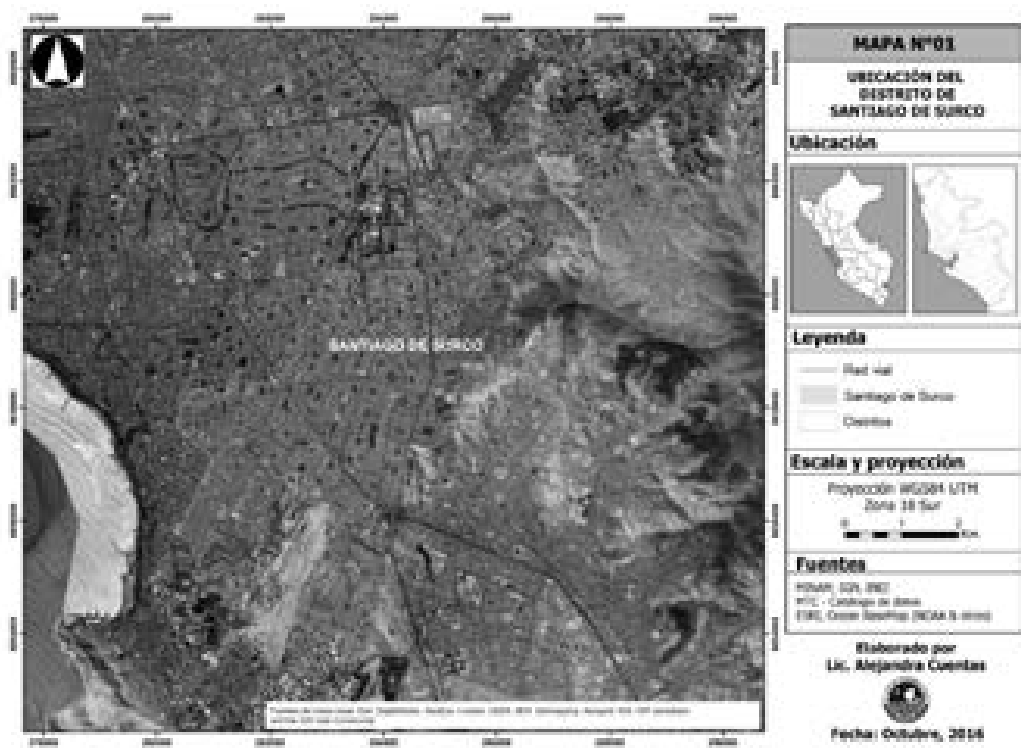

Elaborado por: Alejandra Cuentas

Figura 2.

División de los nueve sectores de Santiago de Surco

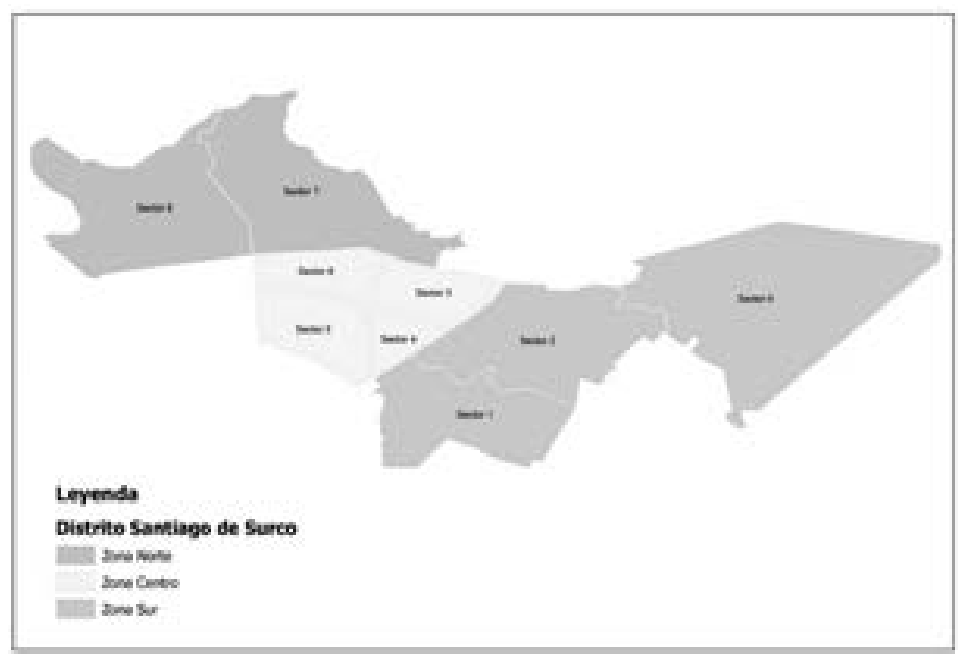


Tabla 1.

Tabla de observación sobre calidad de los espacios públicos en los parques de Santiago de Surco

\begin{tabular}{|c|c|c|c|}
\hline \multicolumn{4}{|l|}{ Criterio: Sociabilidad } \\
\hline Agradable/acogedor & Sí & No & \\
\hline Administración adecuada & Sí & No & \\
\hline \multicolumn{4}{|l|}{ Criterio: Usos y actividades } \\
\hline Activo & Sí & No & $\begin{array}{l}\text { Tipos de } \\
\text { actividades }\end{array}$ \\
\hline Celebraciones/festividades & Sí & No & Veces por semana \\
\hline Sostenibilidad & Sí & No & $\begin{array}{l}\text { Tachos } \\
\text { segregadores }\end{array}$ \\
\hline \multicolumn{4}{|c|}{ Criterio: Comodidad e imagen } \\
\hline Limpio & Sí & No & \\
\hline Verde & Sí & No & Tipo de cobertura \\
\hline Caminable & Sí & No & \\
\hline Atractivo & Sí & No & \\
\hline \multirow[t]{3}{*}{ Acondicionamiento } & Luz & & \multirow[t]{3}{*}{ Observaciones: } \\
\hline & Bancas & & \\
\hline & Basurero & & \\
\hline \multicolumn{4}{|l|}{ Serenazgo } \\
\hline \multicolumn{4}{|l|}{ Criterio: Acceso y conexión } \\
\hline Continuidad/proximidad & Sí & No & \multirow[t]{3}{*}{ Observaciones: } \\
\hline Conexión & Sí & No & \\
\hline Señalética & Sí & No & \\
\hline
\end{tabular}

Elaboración propia. 


\section{Resultados: caracterización general del objeto de estudio}

La primera parte de los resultados obtenidos consiste en el material elaborado para representar los parques seleccionados. En primer lugar, se presenta un cuadro resumen de información de importancia (ver Tabla 2) con datos de área y referencias de ubicación. Luego se presenta cada parque con un mapa respectivo e imágenes registradas en la salida de campo.

Tabla 2.

\section{Información de parques seleccionados}

\begin{tabular}{|l|c|l|}
\hline Nombre del parque & $\begin{array}{c}\text { Área } \mathbf{( m}^{\mathbf{2}} \mathbf{} \\
\text { aproximada }\end{array}$ & \multicolumn{1}{c|}{ Referencias viales } \\
\hline Parque Casuarinas & 8130 & $\begin{array}{l}\text { Entre la calle Araroba y el jirón } \\
\text { Jacarandá. Cerca de la Panamericana } \\
\text { Sur. }\end{array}$ \\
\hline Parque La Alborada & 31800 & $\begin{array}{l}\text { Entre la Alameda del Sereno y la } \\
\text { Alameda del Arco Iris. Cerca de la } \\
\text { Avenida Higuereta. }\end{array}$ \\
\hline Parque Del Leonismo & 13300 & $\begin{array}{l}\text { Entre calles El Carmelo y María Luisa, } \\
\text { cerca de la Avenida La Encalada. }\end{array}$ \\
\hline $\begin{array}{l}\text { Parque Marco } \\
\text { Schenone }\end{array}$ & 15000 & $\begin{array}{l}\text { Entre la calle Bartolomé Ruiz y el Jirón } \\
\text { Jerónimo de Aliaga Sur, cerca de la } \\
\text { Panamericana Sur. }\end{array}$ \\
\hline Parque Perú & 17730 & $\begin{array}{l}\text { Entre los jirones Augusto Wiese y } \\
\text { Santiago Antúnez de Mayolo, cerca de la } \\
\text { Avenida Santiago de Surco. }\end{array}$ \\
\hline Parque de La Amistad & 39000 & $\begin{array}{l}\text { Entre las avenidas Caminos del Inca y } \\
\text { Las Nazarenas. }\end{array}$ \\
\hline
\end{tabular}

Fuente: Google Earth. Elaboración propia. 


\subsection{Parque Casuarinas}

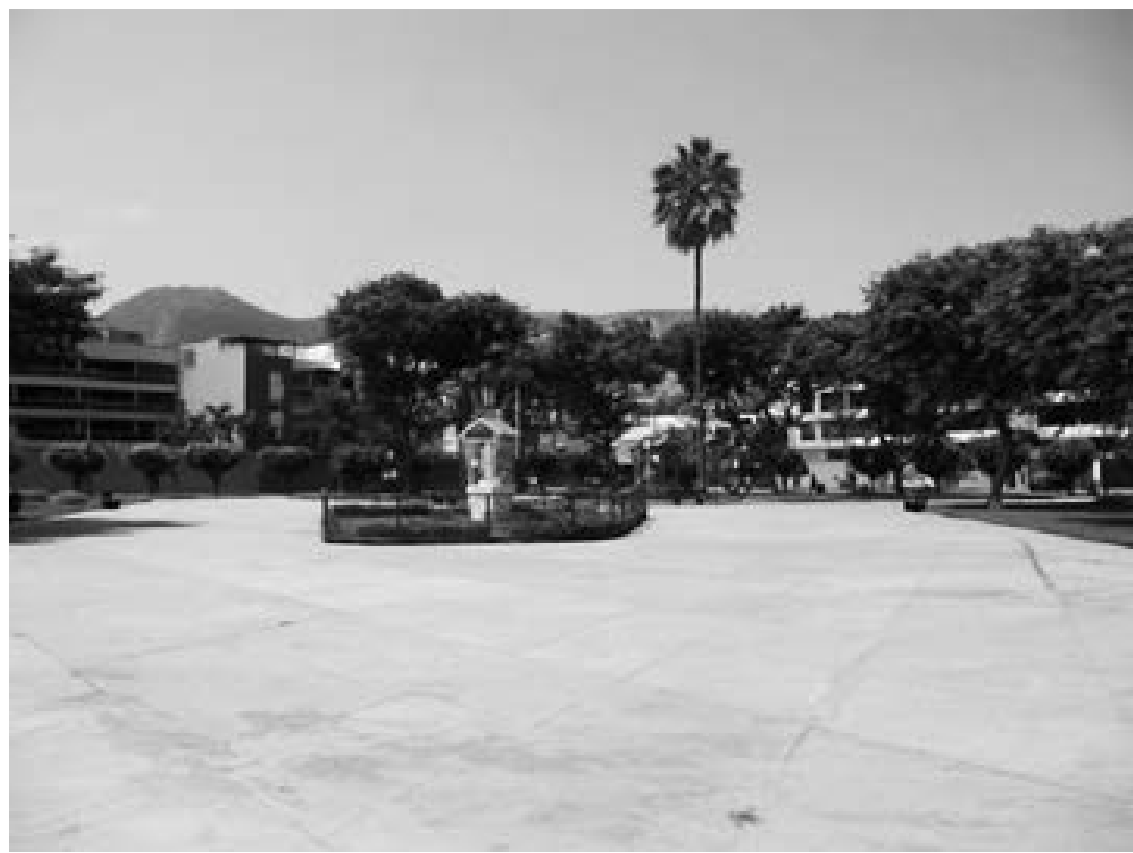

Parque Casuarinas

Foto 1: Ana Sabogal

Si bien no hay mucha información sobre este parque, pero por lo observado e investigado este es muy valorado por los habitantes locales principalmente por dos razones: la primera, por estar ubicado en una zona donde se han establecido gran cantidad de edificios, cuyos departamentos tienen vista a este parque. En segundo lugar, este parque, junto con los parques Libertad 1, César Vallejo, Paz Cafferata y Villa Libertad, es escenario de actividades como aeróbicos, baile, gimnasia, entre otros; las cuales forman parte del programa del distrito denominado Actívate al Aire Libre, que tiene planeado extenderse a otros parques del distrito (Surco Mi Hogar 2015). 
ESPACIOS PÚBLICOS: ESTUdio EN EL DISTRITO DE SANTIAGo DE SURCo EN Lima, Perú / Ana SABogal y otros

Figura 3.

\section{Parque Casuarinas, Santiago de Surco}
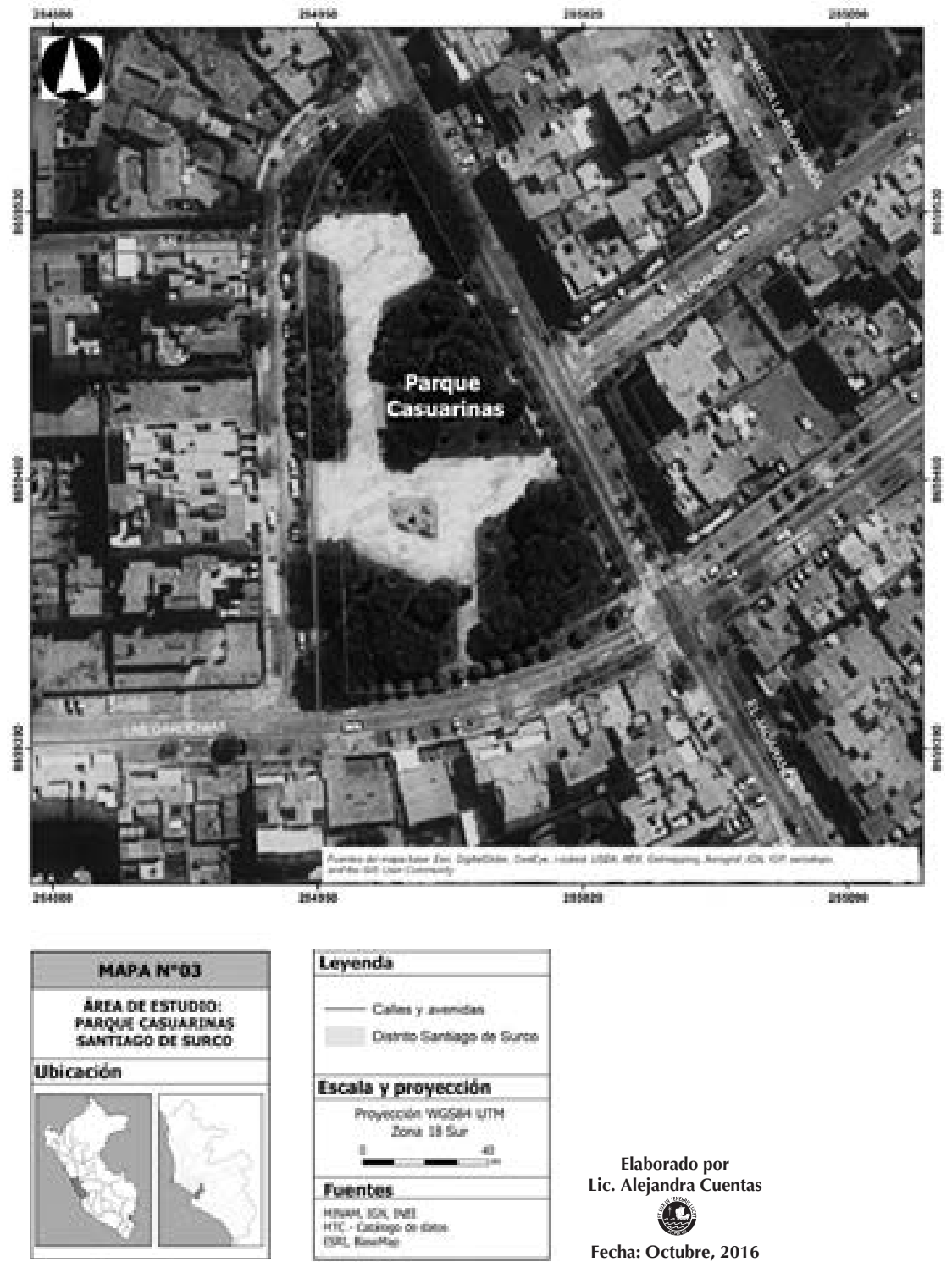

Elaborado por

Lic. Alejandra Cuentas

(1).

Fecha: Octubre, 2016 


\subsection{Parque La Alborada}

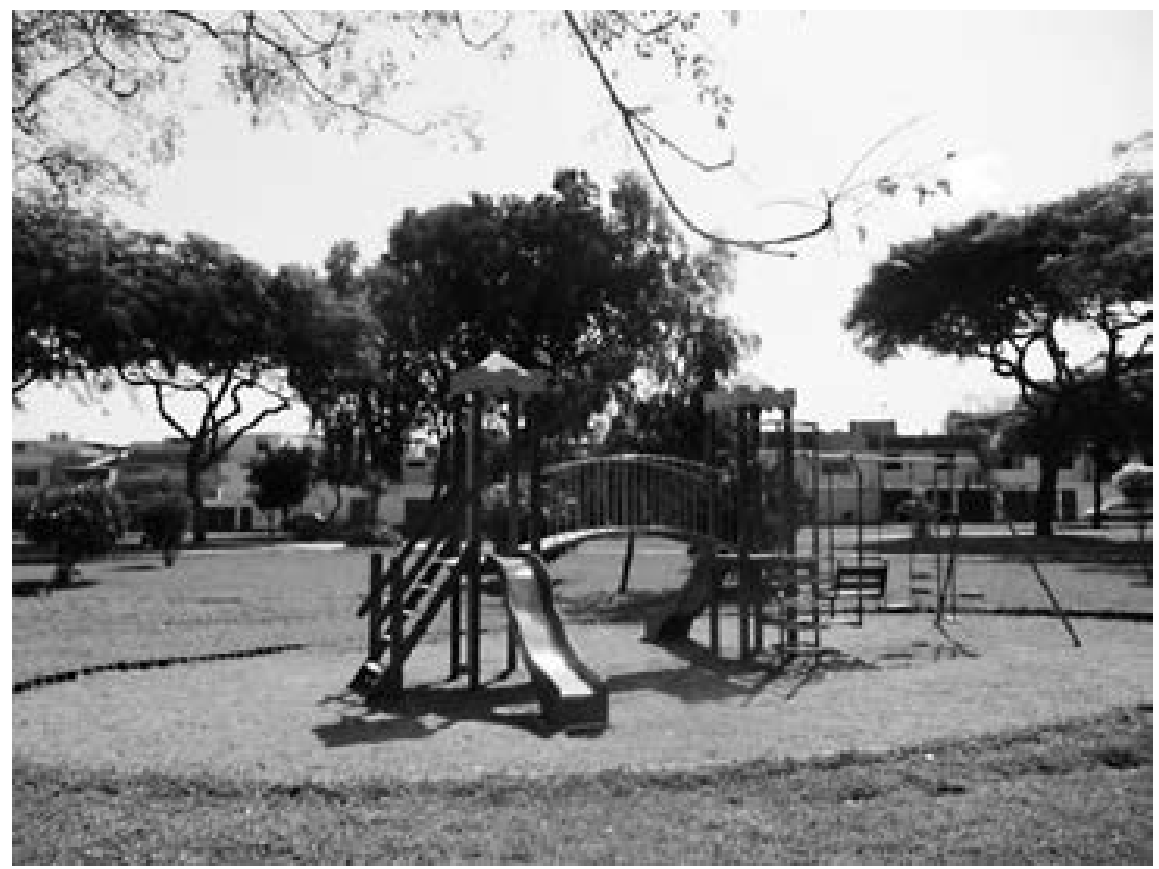

Parque La Alborada

Foto 2: Ana Sabogal

Una particularidad de este parque es que en él se llevó a cabo en una temporada la Bioferia de alimentos orgánicos. Esta fue instalada en el año 2009 por la Municipalidad y la Red de Agricultura Ecológica del Perú - RAE PERÚ (Surco Perú 2017a). Si bien actualmente ya no es el escenario de esta feria de productos ecológicos, gracias a dicha actividad se convirtió en un punto de encuentro y concentración de habitantes importante que sigue siendo considerado por los ciudadanos, por lo que puede ser tomado en cuenta para que se realicen nuevas actividades, ya sea de la misma índole o de temas culturales. 
ESPACIOS PÚBLICOS: ESTUdio EN EL DISTRITO DE SANTIAGo DE SURCo EN Lima, Perú / ANA SABogal y otros

Figura 4.

\section{Parque La Alborada, Santiago de Surco}
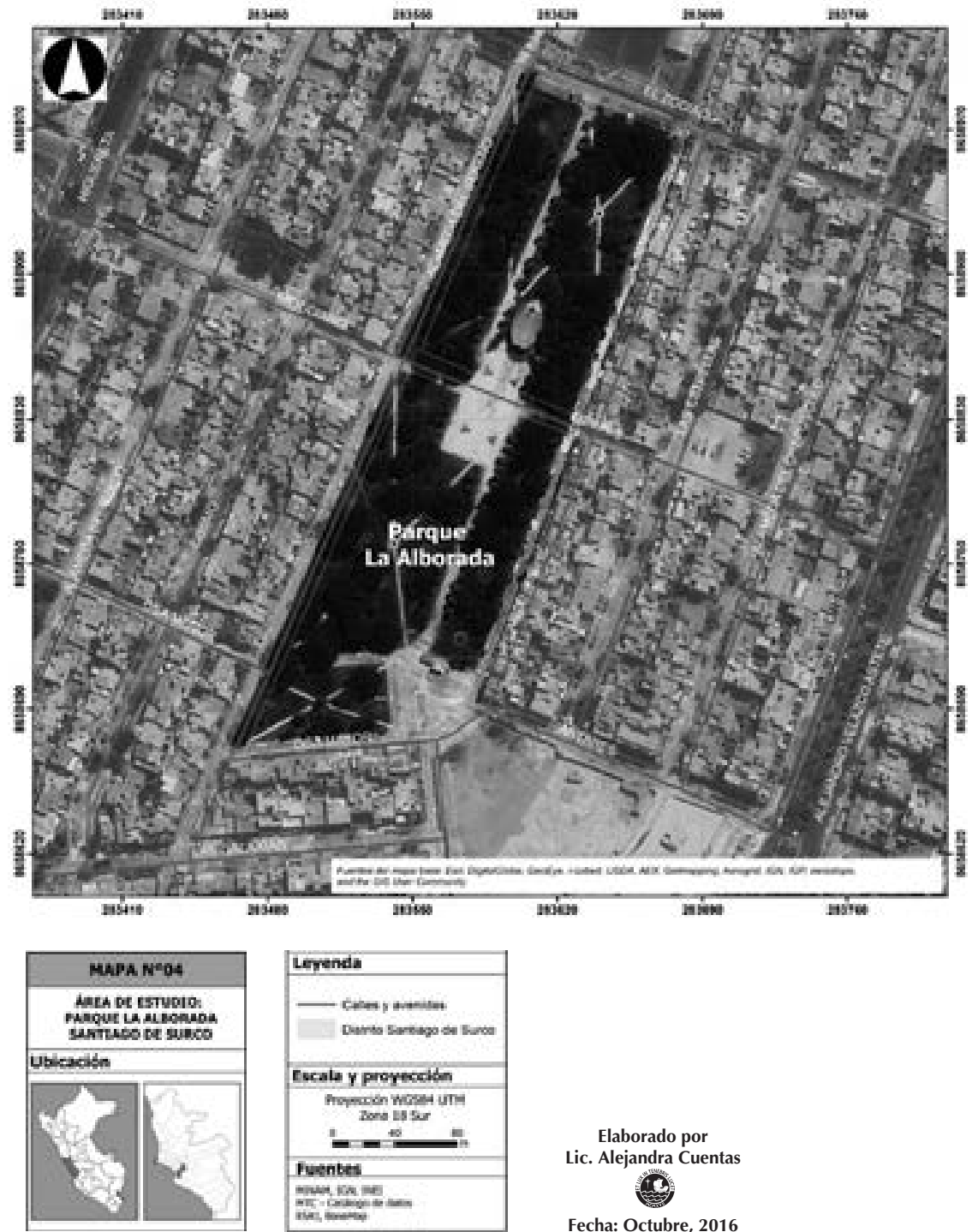

Elaborado por Lic. Alejandra Cuentas

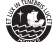

Fecha: Octubre, 2016 


\subsection{Parque Del Leonismo}

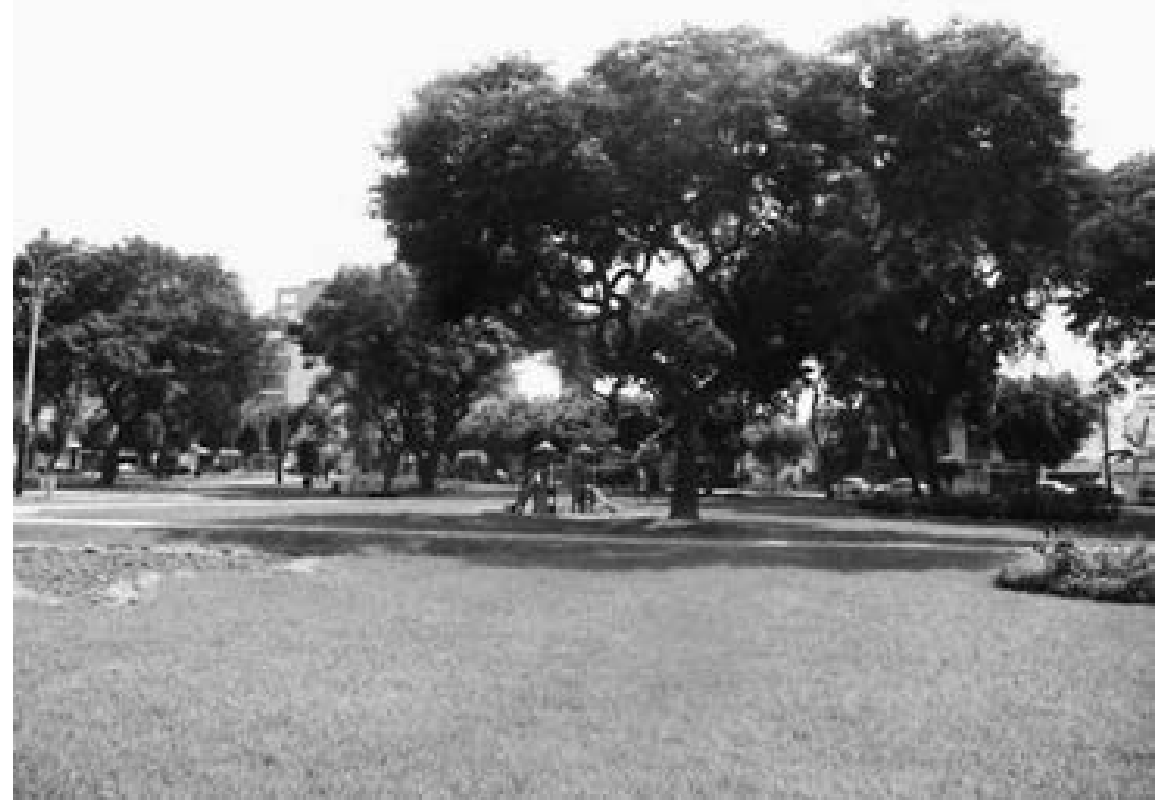

Parque Del Leonismo, Santiago de Surco

Foto 3: Ana Sabogal

Este parque también ha sido escenario de diversas actividades sociales. Una de estas actividades es la feria de mascotas y vacunación gratuita realizada en 2016 (Surco Mi Hogar 2016b). Otra actividad realizada en este parque fue la celebración por fiestas patrias, encargándose los vecinos de la zona de vestir a los árboles de varios parques de blanco y rojo (Surco Mi Hogar 2016a). 
ESPACIOS PÚBLICOS: ESTUdio EN EL DISTRITO DE SANTIAGo DE SuRCo en Lima, Perú / Ana Sabogal y otros

Figura 5.

Parque Del Leonismo, Santiago de Surco

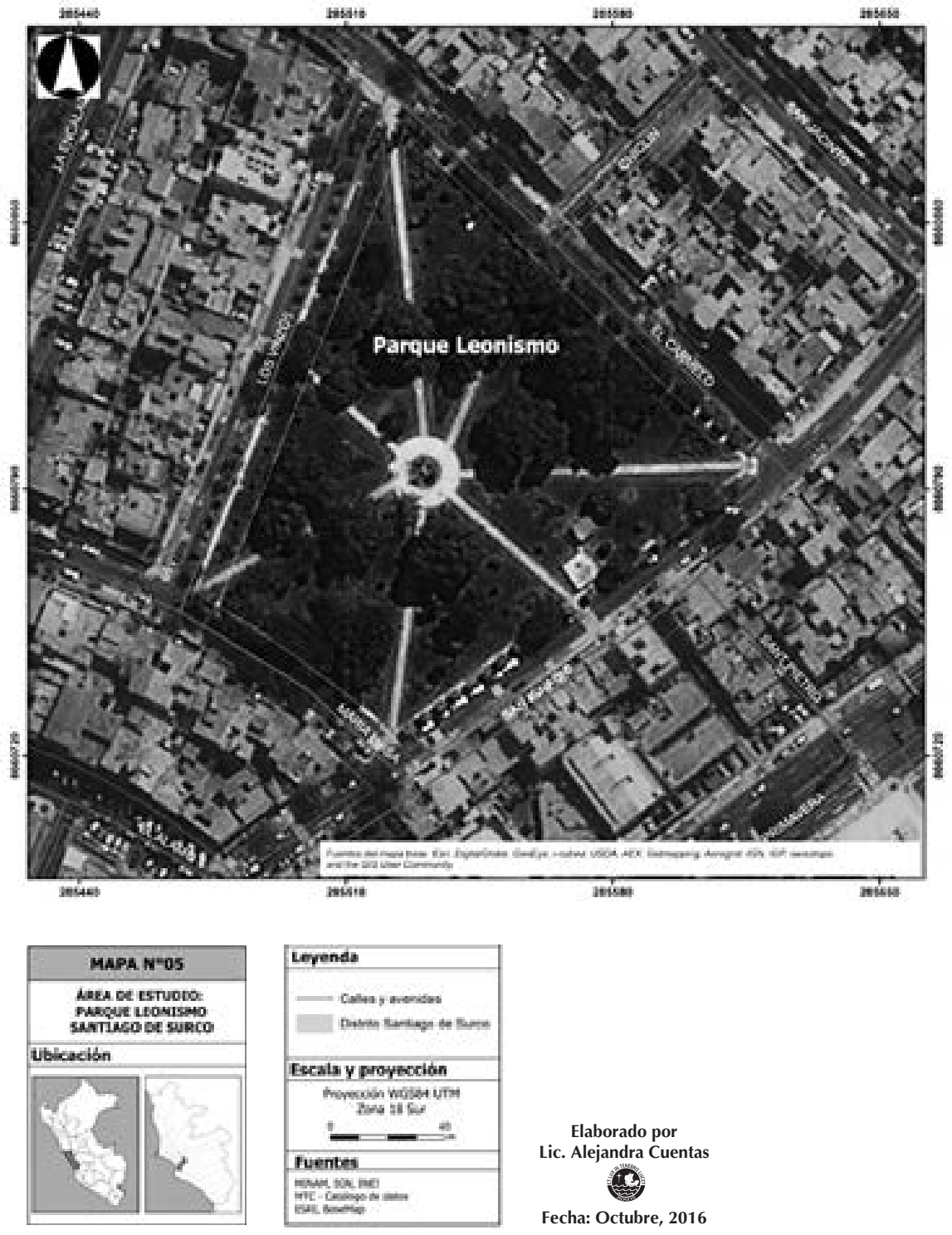




\subsection{Parque Marco Schenone}

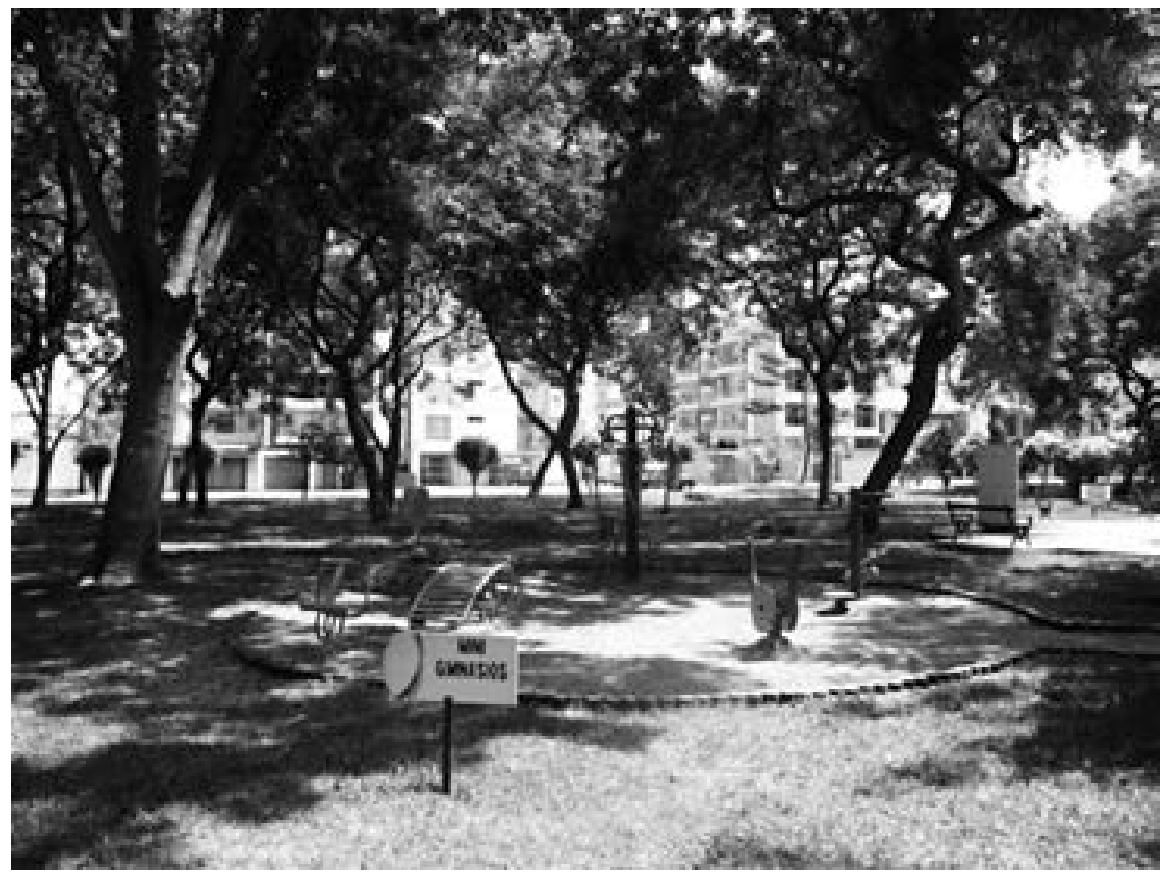

Parque Marco Schenone

Foto 4: Ana Sabogal

De las diversas actividades o proyectos emprendidos y realizados por la municipalidad de Surco y los habitantes del distrito, el parque Marco Schenonne fue el escenario piloto de la estrategia municipal llamada Vecino Vigilante, siendo el área geográfica en la cual los vecinos podían «observar, fiscalizar y monitorear a través de sus celulares todos los movimientos y hechos que registran las cámaras de videovigilancia de los Bolsones de Seguridad del distrito» (Radio Capital 2016). 
ESPACIOS PÚBLICOS: ESTUdio EN EL DISTRITO DE SANTIAGo DE SURCo EN Lima, Perú / Ana SABogal y otros

Figura 6.

Parque Marco Schenone, Santiago de Surco
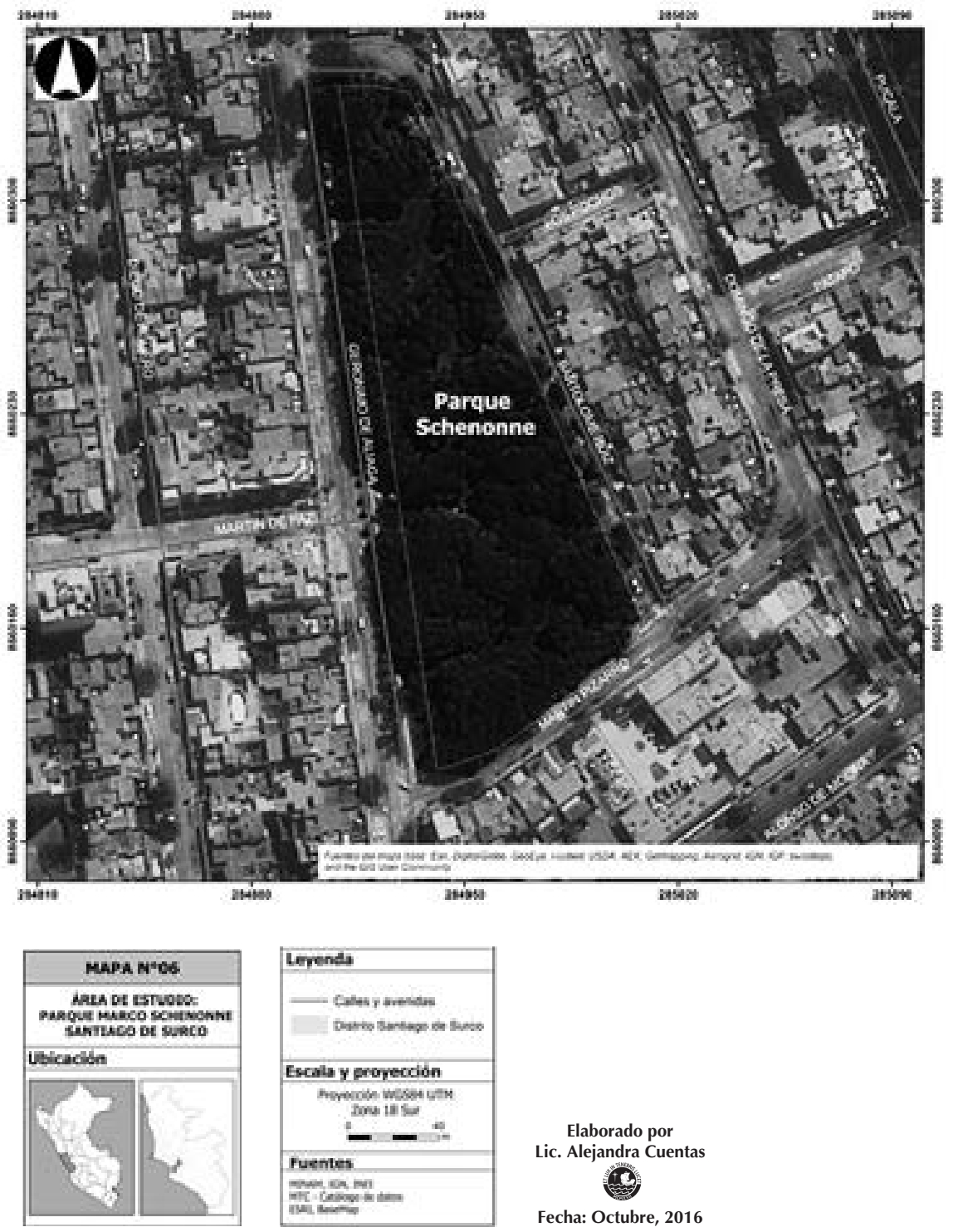

Elaborado por

Lic. Alejandra Cuentas

(t)

Fecha: Octubre, 2016 


\subsection{Parque Perú}

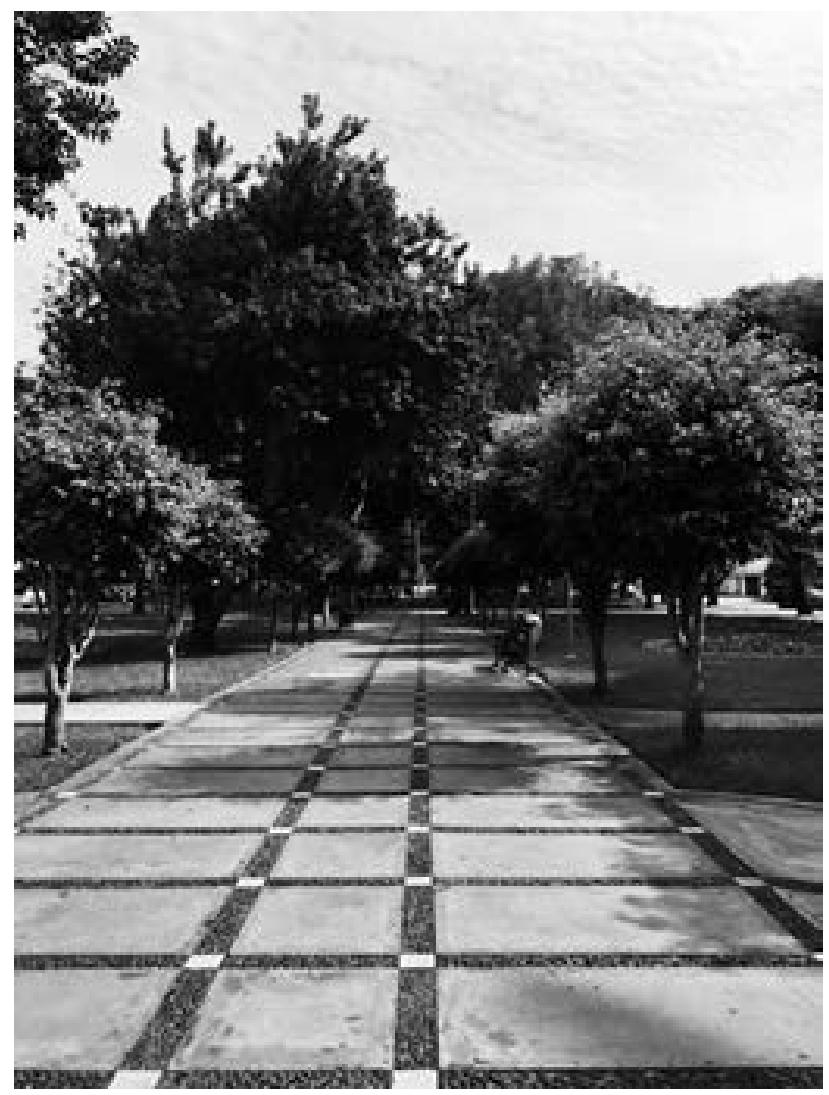

Parque Perú

Foto 5: Ana Sabogal

Si bien no se ha podido encontrar mucha información sobre el Parque Perú, se conoce que es una de las zonas más populares de establecimiento de edificios para actividades empresariales y de negocio, combinadas en parte con zonas residenciales (PlaceDigger-Perú s.a.). 
ESPACIOS PÚBLICOS: ESTUdio EN EL DISTRITO DE SANTIAGo DE SURCo

EN Lima, Perú / Ana SABogal y otros

Figura 7.

\section{Parque Perú, Santiago de Surco}
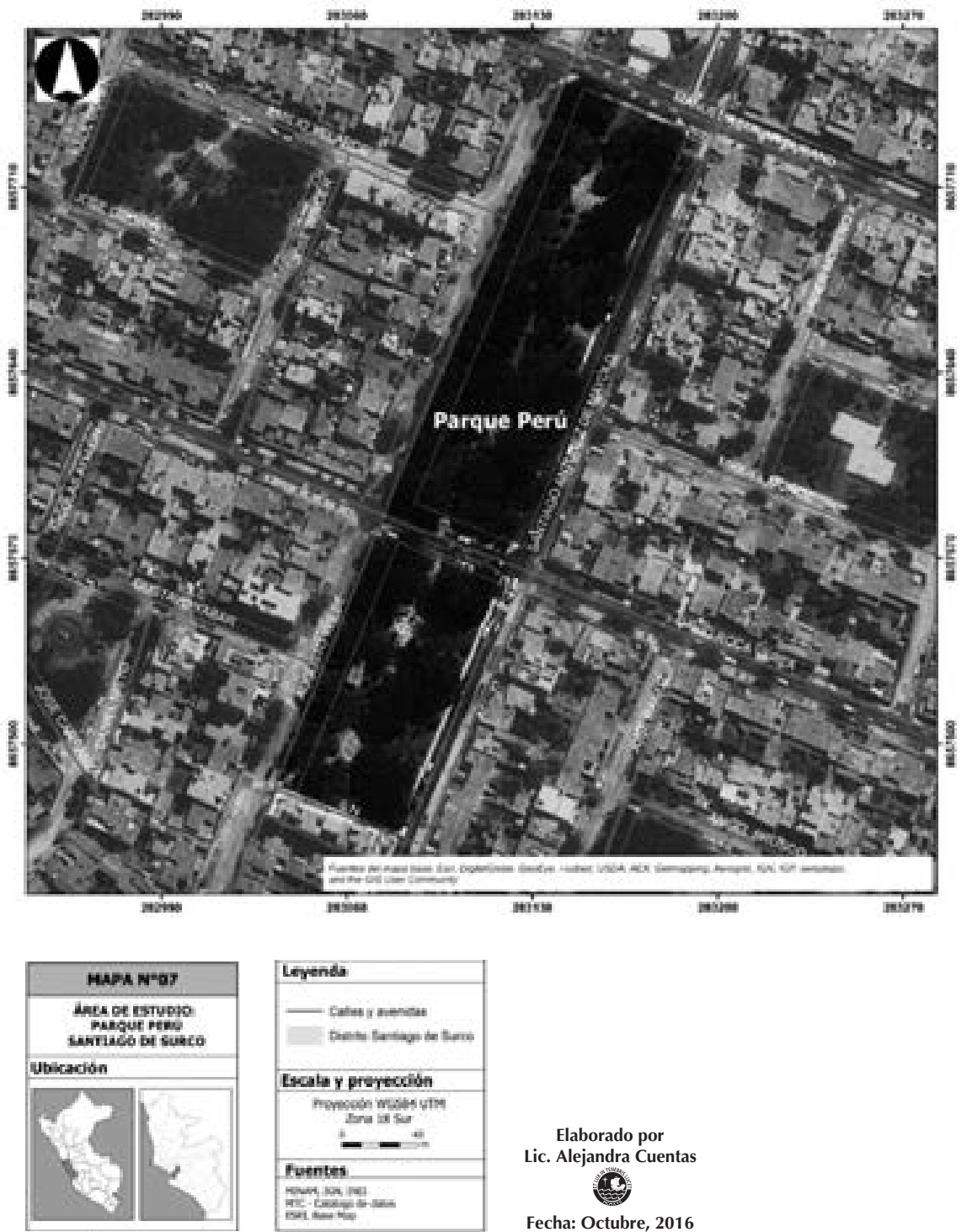

Elaborado por

Lic. Alejandra Cuentas

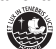

Fecha: Octubre, 2016 


\subsection{Parque de La Amistad}

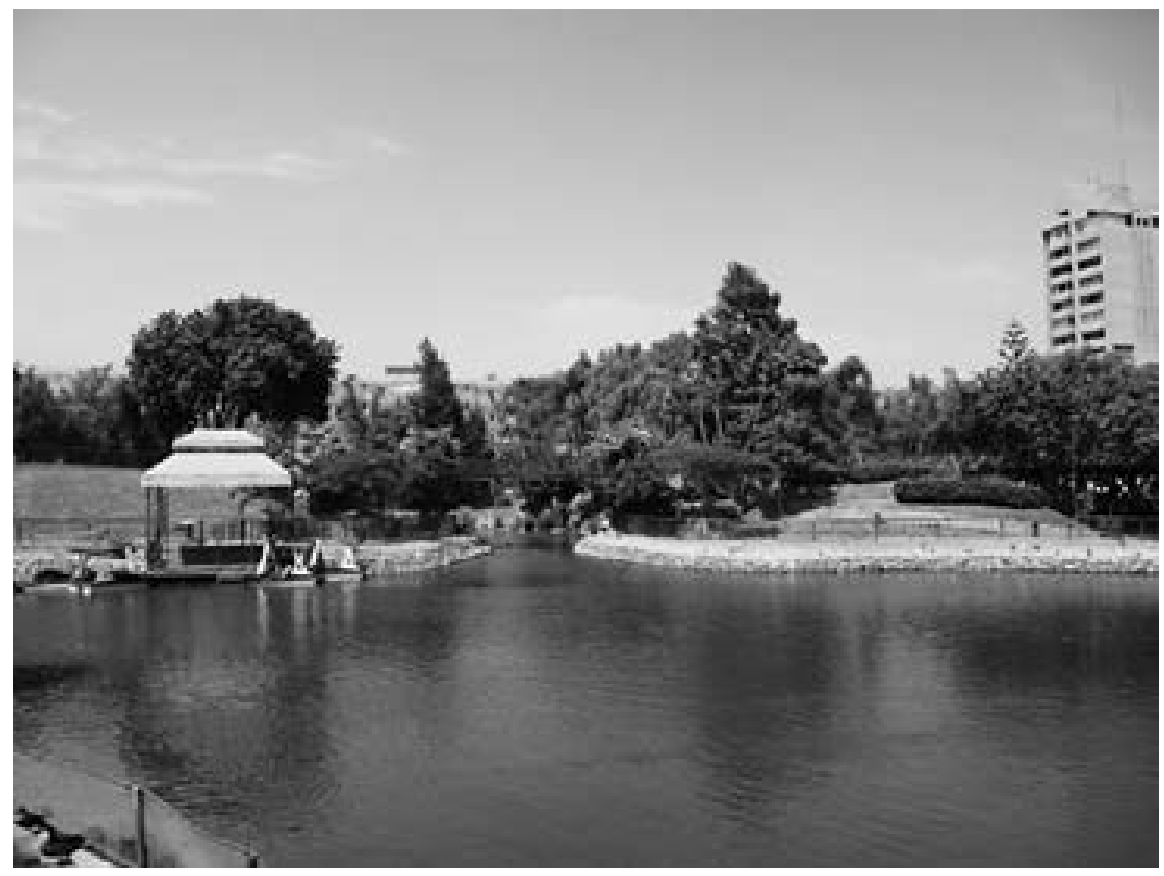

Parque de La Amistad

Foto 6: Ana Sabogal

Este parque se considera el más importante del distrito de Santiago de Surco. Ello se debe a su diversidad cultural, sus amplias áreas verdes y vías de circulación, además de la infraestructura y equipamiento con las que cuenta: plazuelas, piletas, glorietas, caídas de agua, zonas de remanso, juegos infantiles y vagones (Surco.net s. a.). Sus principales atracciones son el Arco Morisco, el tren a vapor, los botes a pedal y la laguna artificial (DePeru. com s.a.; Surco.net, s.a.). También posee una réplica del antiguo pueblo de Surco, Finalmente, cumple la función de un encuentro cultural, ya que en él se presentan obras de teatro y otras actividades culturales (Surco.net s.a.). 
ESPACIOS PÚBLICOS: ESTUdio EN EL DISTRITO DE SANTIAGo DE SURCo EN Lima, Perú / Ana SABogal y otros

Figura 8.

Parque de La Amistad, Santiago de Surco

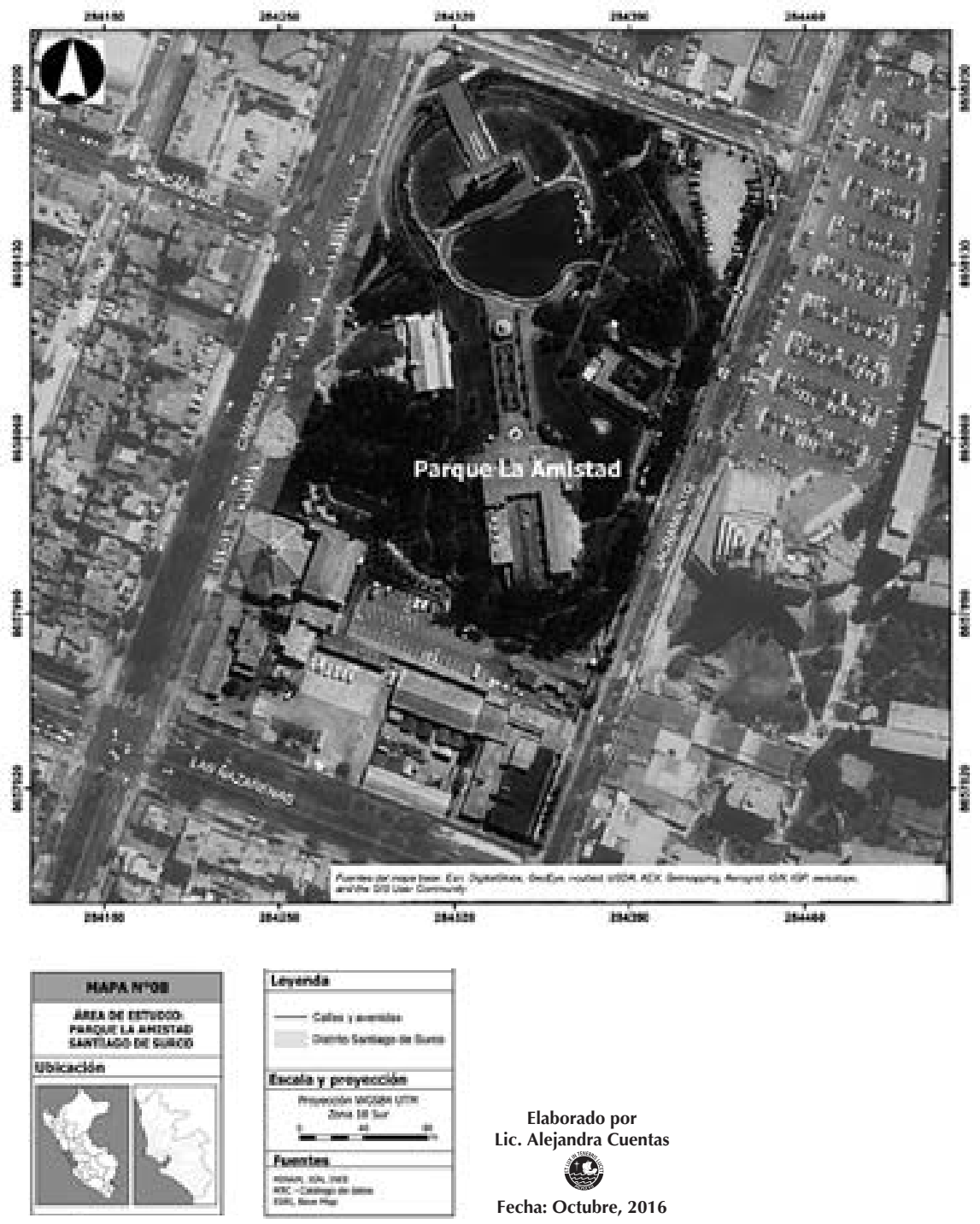




\section{Resultados: calidad de los espacios-objeto de estudio según observación y evaluación}

En relación a los resultados obtenidos de la evaluación de calidad de los parques mencionados de Santiago de Surco, se evidencia que ningún parque cumple todos los criterios sobre calidad de la Tabla 3; no obstante, el parque de La Amistad obtiene la gran mayoría de criterios. En líneas generales, los seis parques cumplen la definición sobre espacio público del presente artículo; ya que presentan accesibilidad, áreas verdes y son abiertos al público. No obstante, en ciertos criterios de calidad como gestión de residuos mediante tachos segregadores, solo el parque de La Amistad se encuentra equipado con ellos.

Tabla 3 .

Criterios para definir calidad en los parques de Santiago de Surco, Lima.

\begin{tabular}{|l|c|c|c|c|c|c|}
\hline $\begin{array}{c}\text { Criterio de calidad/ } \\
\text { Parque }\end{array}$ & Casuarinas & $\begin{array}{c}\text { La } \\
\text { Alborada }\end{array}$ & Leonismo & Schenone & Perú & $\begin{array}{c}\text { La } \\
\text { Amistad }\end{array}$ \\
\hline Sociabilidad & & Sí & Sí & Sí & Sí & Sí \\
\hline Activo & Sí & Sí & Sí & Sí & Sí & Sí \\
\hline Actividades culturales & & & & & & Sí \\
\hline Actividades recreativas & Sí & Sí & Sí & Sí & & Sí \\
\hline Actividades deportivas & & Sí & Sí & Sí & & \\
\hline Actividades ambientales & & & & & & \\
\hline $\begin{array}{l}\text { Celebraciones } \\
\text { importantes }\end{array}$ & Sí & Sí & & & & Sí \\
\hline $\begin{array}{l}\text { Gestión de residuos } \\
\text { adecuada }\end{array}$ & & & & & & Sí \\
\hline Limpio & Sí & Sí & Sí & Sí & Sí & Sí \\
\hline Verde & Sí & Sí & Sí & Sí & Sí & Sí \\
\hline $\begin{array}{l}\text { Apto para paseos y } \\
\text { caminatas }\end{array}$ & Sí & Sí & Sí & Sí & Sí & Sí \\
\hline Estética agradable & Sí & Sí & Sí & & Sí & Sí \\
\hline Buen equipamiento & Sí & Sí & Sí & Sí & Sí & Sí \\
\hline Alto nivel de seguridad & & & Sí & Sí & Sí & Sí \\
\hline $\begin{array}{l}\text { Buen acceso para } \\
\text { vecinos y visitantes }\end{array}$ & Sí & Sí & Sí & Sí & Sí & Sí \\
\hline Conexión con grandes vías & Sí & & & Sí & Sí & Sí \\
\hline
\end{tabular}


ESPACIOS PÚblicos: ESTUdio EN El Distrito de SANTIAgo de SuRco EN Lima, PERÚ / Ana SABogal y otros

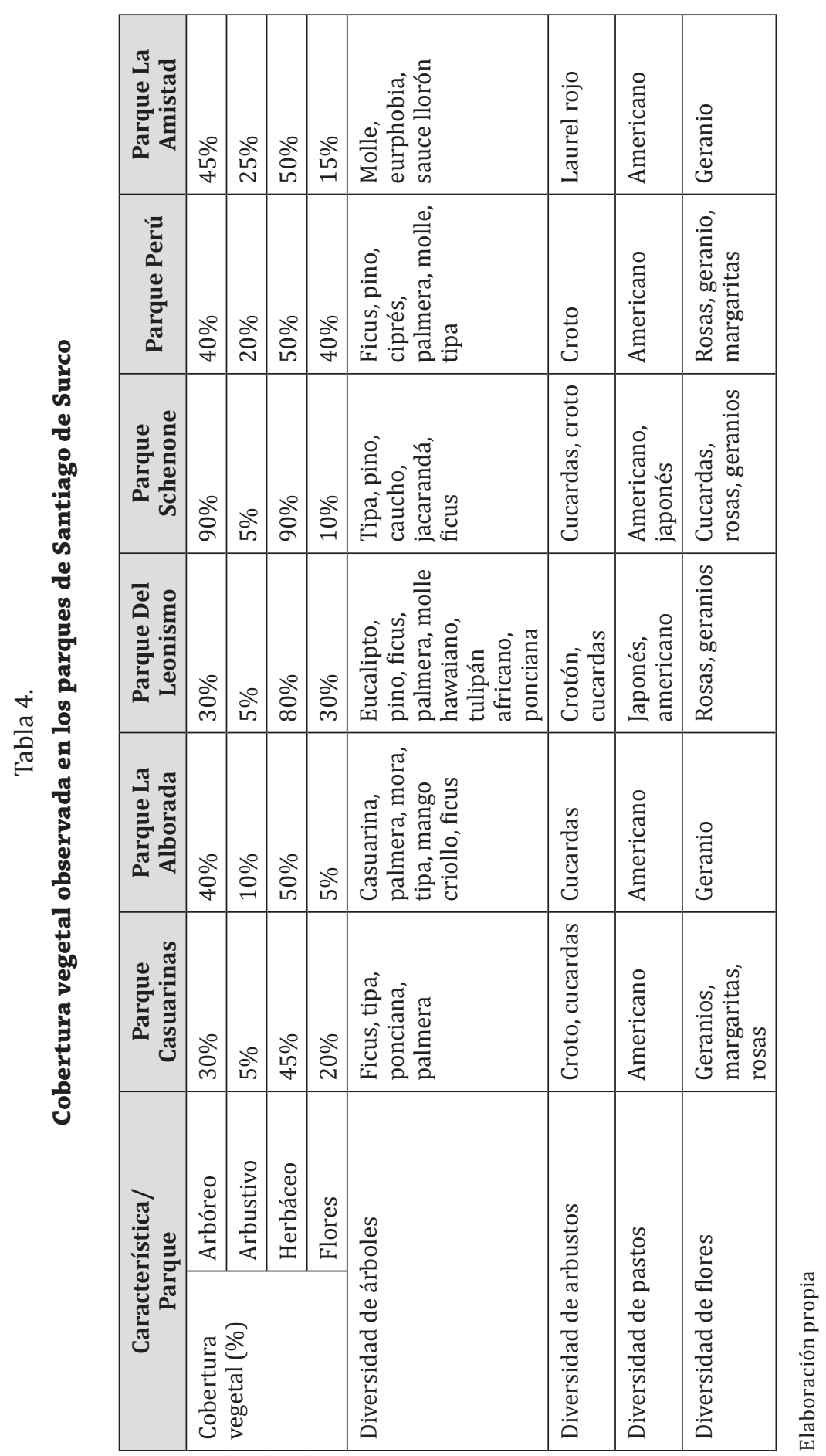




\subsection{Aspectos positivos}

- Con respecto al criterio de sociabilidad, la mayoría de los parques estudiados muestran resultados positivos.

- Según lo observado, la mayoría de los parques está destinado a la recreación.

- $\quad$ Todos los parques, según las observaciones realizadas, se encuentran bien cuidados y limpios.

- Todos los parques cuentan con importante cobertura vegetal, siendo las más predominantes las de tipo arbóreo y herbáceo, con especies introducidas en su mayoría, adecuadas a las condiciones de baja oferta de agua.

- $\quad$ Todos los parques son aptos para paseos y caminatas, siendo además de acceso libre, tanto para vecinos como para transeúntes.

- Excepto uno de los parques, todos cuentan con estética y paisaje agradable.

- En todos los parques se encuentra un adecuado inmobiliario (bancas, iluminación, tachos).

- La mayoría de parques cuenta con seguridad por la presencia del Serenazgo y sistema de vigilancia de la municipalidad.

- Cuatro de los seis parques estudiados se encuentran cercanos a principales avenidas, lo que permite el acceso de vecinos de otros sectores y otros distritos.

\subsection{Deficiencias}

- $\quad$ No se encontró en ninguno de los parques actividades ambientales.

- $\quad$ Solo uno de los parques cuenta con actividades culturales.

- $\quad$ Solo el 50\% de los parques están equipados para realizar actividades deportivas.

- $\quad$ Solo un parque cuenta con una gestión adecuada de residuos (tachos segregadores), lo cual muestra un déficit en gestión ambiental dentro de los espacios públicos del distrito.

\subsection{Discusión}

En la actual normativa legal, la definición de espacio público imposibilita una adecuada discusión de políticas públicas, ya que el diseño de estas es sometido a la normativa de áreas verdes. Según el Reglamento Nacional de Edificación creado por el Decreto Supremo Nro. 011-2006 del Ministerio de 
Vivienda, Construcción y Saneamiento, espacio público es una superficie de uso público, destinada a circulación o recreación (Ministerio de Vivienda, Construcción y Saneamiento, y Servicio Nacional de Capacitación para la Industria de la Construcción, 2006). Esta definición comprende desde una calle hasta un parque, ya que, estos lugares son públicos y destinados a la circulación o recreación; además, este reglamento es la única herramienta legal que define el concepto de espacio público. Esto evidencia la ausencia total de una normativa legal acerca del tema y la articulación de la definición del concepto.

En el marco del proceso de descentralización, los diferentes niveles de gobierno han desarrollado cierta autonomía en la gestión pública; por ejemplo, la gestión ambiental en el nivel distrital. La implementación de espacios públicos en el ámbito distrital depende de la capacidad de las municipalidades y la demanda de la población. Hace falta un aparato estatal que logre diseñar herramientas legales que incluyan las distintas dimensiones de este concepto, físico-territorial, político, social, económico y cultural (Takano et al. 2007). Por otro lado, falta involucrar e identificar las prioridades y la demanda de los vecinos. Este punto resulta esencial para lograr la pertinencia del diseño de una política pública. Por ejemplo, en el distrito del Rímac, que tiene un gran potencial para la promoción de espacios públicos por su centro histórico declarado como Patrimonio Mundial por la UNESCO, pero donde no sería prioridad ni pertinente el diseño de una política pública en torno al tema si no se considera como problema público. En los últimos años, el Rímac ha sido uno de los distritos que ha presentado altos índices de inseguridad ciudadana (Bazán et al. 2015), lo que conlleva a que la promoción de espacios públicos no se defina como prioridad. Cabe resaltar que existe una relación directa entre la seguridad y el uso de los espacios públicos.

La ausencia de antecedentes directos relacionados con la promoción de espacios públicos como ordenanzas municipales o leyes no imposibilita el diseño de una política pública relacionada con el tema; ya que, el diseño de esta se puede discutir a partir de un marco legal que justifique su necesidad. En esta línea la, «Ley General del Ambiente» (Ley 28611) enuncia en su primer artículo lo siguiente: «toda persona tiene el derecho irrenunciable de vivir en un ambiente saludable, equilibrado y adecuado para el pleno desarrollo de la vida [...]» (Ministerio del Ambiente 2005: 20); y el inciso 22 del artículo 2 de la «Constitución Política del Perú» (1993) enuncia lo siguiente: «toda persona tiene derecho a la paz, a la tranquilidad, al disfrute del tiempo libre y al descanso, así como a gozar de un ambiente equilibrado y adecuado al desarrollo de su vida». Estos dos argumentos legitiman la necesidad de espacios públicos y reconocen los derechos de los ciudadanos. 
Figura 10.

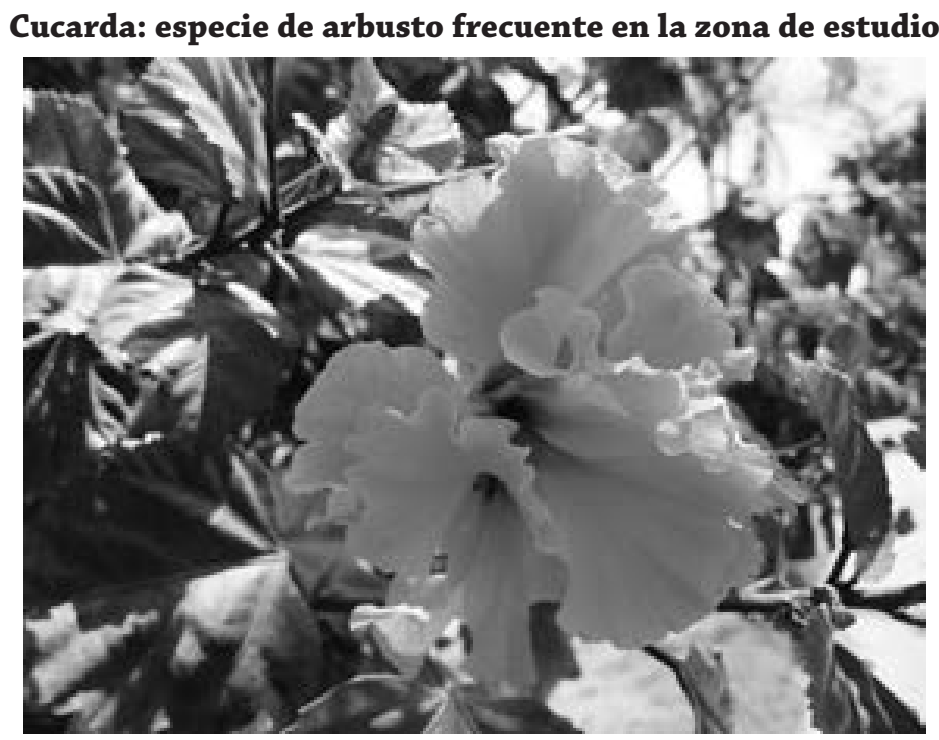

Foto 8: Ana Sabogal

En relación a la definición de espacio público de esta investigación, este debe cumplir las siguientes características: 1) área libre, este espacio no debe presentar ningún tipo de barrera para el ingreso de cualquier persona, es decir, la ausencia de cualquier tipo de barrera como físicas como monetarias que permitan la movilidad libre; 2) área verde, este espacio debe contemplar un mayor porcentaje de vegetación, no obstante, el porcentaje de césped debe ser menor al 50\% y el área de cemento menor al 20\% del total del área del parque y 3) área pública, la propiedad le pertenece a una administración pública o a un Organismo Público Descentralizado como el Servicio de Parques de Lima (SERPAR).

En la actualidad, la gestión ambiental de las municipalidades se rige bajo el Sistema Nacional de Gestión Ambiental (SNGA) del Ministerio del Ambiente (MINAM). Entre la normativa legal del MINAM se encuentra como base normativa la «Ley General del Ambiente» (Ley 28611) que enuncia en el artículo 24 «que los Gobiernos Locales deben implementar el Sistema Local de Gestión Ambiental, sobre la base de los órganos que desempeñan diversas funciones ambientales que atraviesan el Gobierno Local y con la participación de la sociedad civil» (Ministerio del Ambiente 2005: 94).

En este sentido el Sistema Local de Gestión Ambiental (SLGA) tiene con objetivo el desarrollo y la implementación, así como la revisión y corrección, de la política local del ambiente. Las metas de la regulación de las funciones 
de dicha política son la orientación adecuada de la gestión de la calidad ambiental, la conservación de los recursos naturales y el uso sostenible de los mismos, todos en conjunto para garantizar el bienestar poblacional (Andía Chávez et al. 2006).

Este nivel del SNGA establece los parámetros de la gestión ambiental en los espacios locales, las municipalidades. Un claro ejemplo de los parámetros que establece el SNGA es la firma del Acuerdo de París, de alcanzar las metas de los Objetivos de Desarrollo Sostenible; y que se regula mediante ordenanzas municipales. Además, los gobiernos locales deben implementar la Política Ambiental Local para establecer los lineamientos de la gestión ambiental del gobierno local y articularla con los planes de desarrollo local.

En este sentido, la Política Ambiental Local es implementada en el marco de las funciones de la «Ley orgánica de municipalidades» (Ley 27972) y en coordinación con la Comisión Ambiental Regional previa existencia de un Sistema Local de Gestión Ambiental. Respecto a la Comisión Ambiental Regional, esta tiene como función la coordinación y concertación de la política ambiental local; con esto busca promover el diálogo entre los diferentes actores dentro del contexto local (Andía Chávez et al. 2006). Este nivel de gobierno dentro del municipio tiene la función de implementar el plan y la agenda ambiental local, coordinar permanentemente con el gobierno local, y finalmente, adecuar la gestión a la problemática ambiental de la localidad.

La ausencia de una normativa legal sólida y coherente sobre espacio público no es el único problema identificado. El otro gran problema es la gestión de cada gobierno municipal elegido; es decir, la discontinuidad de un plan estratégico institucional y el que la gestión de cada gerencia de la municipalidad dependa de la continuidad del gobierno municipal que elaboró dicho plan e iniciativas. Además, los gobiernos locales se caracterizan por su autonomía en la toma de decisiones, es decir, las municipalidades no generan espacios de diálogo para articular sus políticas de desarrollo urbano; por otro lado, la ausencia de una articulación vertical entre el gobierno regional y local generan islas de buena gestión de desarrollo urbano o políticas sectoriales. Esta situación se evidencia en el Servicio de Parques (SERPAR), Organismo Público Descentralizado de la Municipalidad Metropolitana de Lima, ya que, este organismo fue afectado por el cambio de gestión municipal, lo que se manifestó en un notable quiebre en la continuidad del plan estratégico de la gestión anterior hasta la suspensión temporal del organismo.

En la gestión municipal de Lima Metropolitana de 2011 a 2014 el SERPAR, mediante su Plan Estratégico Institucional 2014-2016, resalta la implementación de nuevos espacios públicos con el objetivo de la creación de espacios para la recreación y la mejora de la calidad de vida de las personas más vulnerables a partir de los parques zonales. En conclusión, el SERPAR 
tenía el objetivo de crear y mejorar los parques zonales como espacios públicos para las personas aledañas a ellos, debido a la ausencia evidente de espacios para la recreación de esta población. Este claro objetivo de fomentar la creación de espacios públicos fue interrumpido abruptamente por el cambio de gestión, desapareciendo como organismo.

En el Plan Estratégico Institucional del SERPAR (2014-2016), tanto la visión a corto plazo como a largo plazo demuestran la creación de espacios públicos mediante la implementación de grandes extensiones de áreas verdes. Según la visión a corto plazo, «los esfuerzos de SERPAR están orientados por una visión consistente en contribuir a hacer Lima una ciudad verde, con espacios públicos formativos y recreativos para todos y una vecindad firmemente unida por su identidad cultural» (SERPAR, 2013: 3). Por otro lado, la visión a largo plazo era la de «fortalecer la gestión del sistema de parques zonales y metropolitanos, mediante la ejecución de proyectos, programas y actividades que desarrollen y promuevan el verde urbano, con la finalidad de contribuir a la integración social, la formación integral y la recreación saludables para todos los vecinos de Lima» (SERPAR, 2013: 3). En conclusión, la política institucional del SERPAR era la de crear nuevos espacios públicos que fomenten la integración de la población por medio de espacios verdes que promuevan la recreación y la interacción entre los vecinos.

En conclusión, el SERPAR era un organismo que pretendía la administración y creación de espacios públicos para la población que se ubicaba en los extremos de la ciudad denominados Lima Norte, Lima Sur y Lima Este, por medio de los parques zonales y metropolitanos. El SERPAR identificaba un claro problema para la continuidad de sus objetivos institucionales: «la gestión y regulación de los espacios públicos se ve afectada en la actualidad por problemas relativos a las instituciones, normas y procesos administrativos de los gobiernos municipales y distritales» (SERPAR, 2013: 11). Este problema confirma lo planteado, la ausencia de una normativa legal sólida y adecuada a la realidad de cada municipio impide la elaboración y planificación de espacios públicos que cumplan los criterios de calidad y su función de espacios de recreación, y mejoren la calidad de vida de los vecinos.

\section{Conclusiones y recomendaciones}

A lo largo del presente artículo se discuten las condiciones necesarias para considerar un parque como espacio público y la situación actual del marco normativo relacionado con ese tema. Asimismo, Se analizan las condiciones actuales de los siguientes parques del distrito de Santiago de Surco: 
Casuarianas, La Alborada, Del Leonismo, Marco Schenone, Perú y La Amistad para evaluar su posibilidad de ser considerados como espacios públicos para los vecinos y los transeúntes.

En relación a la normativa legal, es importante mencionar, tal como lo indica Mayo D'Arrigo (2010), que el espacio público es un concepto que aún no está incluido en la legislación urbana ambiental y municipal; sin embargo, el espacio público está adquiriendo, desde el marco conceptual, una gran importancia en el contexto internacional que debe ser considerado. En efecto, es indudable la ausencia de una normativa específica relacionada con el tema. Tanto Mayo (2010) como Ludeña (2013) evidencian los reducidos aportes del marco normativo sobre los espacios públicos.

El distrito de Santiago de Surco se caracteriza por ser uno de los distritos con mayor área y número de habitantes en Lima Metropolitana; lo cual se evidencia en la cantidad de metros cuadrados de área verde por habitante. Según el inventario de áreas verdes a nivel metropolitano, este distrito posee $4.17 \mathrm{~m}^{2} / \mathrm{hab}$. con áreas verdes. Esta cifra contiene solo los espacios con cobertura verde que son administrados por la municipalidad; cabe resaltar que la Organización Mundial de la Salud (OMS) recomienda $8 \mathrm{~m}^{2} /$ ha. de área verde. Esta información demuestra la reducida oferta de espacios públicos con área verde para los vecinos y los posibles transeúntes; por ello, la adecuación de los parques como espacios públicos permite transformar la noción de aquellos como lugares de ornamento a espacios de esparcimiento e interacción con los vecinos. 


\section{Referencias}

Andía Chávez, J. y W. Andía VAlEncia (2006). Manual de gestión ambiental. Lima: El Saber.

Bazán, C., I. Urrutia, N. Mejía y A. Huaytalla. (2015) Reglamento Nacional de Edificaciones. Decreto Supremo $N^{\circ} 011$-2006-Vivienda.

Constitución Política del Perú. Separata del Diario Oficial El Peruano. Lima, 30 de diciembre de 1993.

DA GAMA, H. (2008). Social and Environmental aspects of peri-urban growth in Latin American megacities. United Nations Expert Group Meeting on Population Distribution, Urbanization, Internal Migration and Development. Department of Economic and Social Affairs. New York.

Decreto Supremo Nº11-2006. Aprueban 66 normas técnicas del reglamento nacional de edificaciones. Separata del Diario Oficial El Peruano. Lima, 8 de mayo de 2006.

DePeru.com (s.a.). «Parque de la Amistad (Santiago de Surco)». Recuperado de:http://www.deperu.com/esparcimiento/centros-recreacionales/ parque-de-la-amistad-santiago-de-surco-2559

ECOLOGisTAS EN ACCión (2008). «¿Qué son las PM2,5 y cómo afectan a nuestra salud?»Recuperado de: https://www.ecologistasenaccion.org/?p=17842

Instituto NACIONAL DE Estadística E Informática (INEI) (2008). Provincia de Lima: Compendio Estadístico, 2011-2012.

InSTITUTO NACIONAL DE Estadística E InFormática (INEI). (2015). Indicadores estadísticos de seguridad ciudadana. Lima Centro.

InStituto Metropolitano DE Planificación. (2010). «Inventario de áreas verdes a nivel Metropolitano». Recuperado de: http://www.urbanistasperu.org/ $\mathrm{imp} /$ inventariodeareasverdes/PDF/Inventario\%20de\%20Areas $\% 20$ Verdes\%20a\%20nivel\%20Metropolitano.pdf

Ley General Del Ambiente, №28611 (2005). Ley Marco del Sistema Nacional de Gestión Ambiental - Ley N²8245. Reglamento de la Ley Marco del Sistema Nacional de Gestión Ambiental - Decreto Supremo Nº 008 - 2005 - PCM. Ley de Creación, Organización y Funciones del Ministerio del Ambiente Decreto Legislativo $\mathrm{N}^{\circ} 1013$. Recuperado de: http://www.minam.gob.pe/ wp-content/uploads/2013/06/ley-general-del-ambiente.pdf

LEY ORGÁNICA DE MUNICIPALIDADES, N²7972 (2003). Recuperado de: http://www. peru.gob.pe/Nuevo_Portal_Municipal/portales/Municipalidades/1340/ entidad/PM_MUNICIPALIDAD_DETALLE.asp?pk_id_entidad $=1340 \& p k$ _ id_tema $=79171 \&$ pk_id_sub_tema $=7800$

Lima cómo vamos (2014). «Evaluando la gestión de Lima: quinto informe de resultados sobre la calidad de vida». Recuperado de: http:// www.limacomovamos.org/cm/wp-content/uploads/2015/01/ EncuestaLimaComoVamos2014.pdf 
ESPACIOS PÚBLICOS: ESTUDIO EN EL DISTRITO DE SANTIAGO DE SURCO en Lima, Perú / Ana Sabogal y otros

Liebenthal, A. y D. Salvenini (2011). Promoting Environmental Sustainability in Peru: a review of the World Bank Group's Experiences (2003-2009). World Bank, Independent Evaluations Group. IEG working Paper 2011, №1. Washington DC

LudeÑa URquizo, W. (2013). Lima y espacios públicos: perfiles y estadística integrada 2010. Lima: Pontificia Universidad Católica del Perú, Facultad de Arquitectura y Urbanismo, Oficina de Publicaciones.

Mayo D’Arrigo, M. (2010). Áreas verdes y espacios públicos. Lima: Defensoría del Pueblo.

Ministerio del Ambiente (2012). Informe del Estado del Ambiente 2009-2011. Lima: MINAM.

Ministerio de Vivienda, Construcción y Saneamiento y Servicio Nacional de CAPACITACIÓN PARA LA INDUSTRIA DE LA CONSTRUCCIÓN (2006) Reglamento Nacional de Edificaciones. Decreto Supremo $N^{\circ} 011-2006-V i v i e n d a$.

Municipalidad de Santiago de Surco (2013). Compendio Estadístico Municipal 2013. Gerencia de Planeamiento, Presupuesto y Desarrollo Institucional. Subgerencia de Planeamiento y Racionalización. Recuperado de: http://www.munisurco.gob.pe/municipio/laGestion/transparencia/ compendios_estadisticos/compendio_estadistico_municipal_2013.pdf

Radio Capital (2016). "Vecinos de Surco accederán a imágenes de cámaras de seguridad para denunciar robos». Recuperado de: http://www. capital.com.pe/actualidad/vecinos-de-surco-accederan-a-imagenesde-camaras-de-seguridad-para-denunciar-robos-noticia-847668, 15 de marzo.

Romero, R. (2017). «Lima tiene un déficit de 56 millones de metros cuadrados de áreas verdes». Recuperado de: https://rpp.pe/data/lima-tieneun-deficit-de-61-millones-de-metros-cuadrados-en-areas-verdesnoticia-1021931.

Servicio de Parques de Lima. (2013). Plan estratégico institucional 2014-2016. Lima: SERPAR.

PlaceDigger-Perú (s.a.). «Parque Perú,VistaAlegre,Surco». Recuperadode:http:// pe.placedigger.com/parque-peru-vista-alegre-surco1617225813.html

Surco Mi Hogar (2015). «Disfruta y ejercítate esta semana con Actívate al aire Libre. Municipalidad de Santiago de Surco. Surco Verde». Recuperado de: http://www.munisurco.gob.pe/surco_portal/municipio/app/2015_ agosto/07_05_ago_activate_aire_libre.html

Surco Mi Hogar (2016a). «Más de 100 familias embanderan árboles de trece parques surcanos». Recuperado de: http://www.munisurco.gob.pe/ surco_portal/municipio/app/2016/12-diciembre/51_(15-dic)_feria_ mascotas_parque_leonismo.html 
Surco Mi Hogar (2016b). «Realizarán Feria de Mascotas y vacunación gratuita en Parque del Leonismo». Recuperado de: http://www.munisurco.gob. pe/surco_portal/municipio/app/2016/12-diciembre/51_(15-dic)_feria_ mascotas_parque_leonismo.html

Surco. Net (s.a.). «El Parque de la Amistad. Distrito Histórico, Cultural y Turístico». Recuperado de: http://www.surco.net/informacion-turistica/parquede-la-amistad.htm

Surco Perú (2017a). «Bioferia en Surco, alimentos orgánicos en Surco». Recuperado de: http://www.surcoperu.com/turismo-surco-lima-peru/ bioferia-feria-ecologica-surco.php

Surco Perú (2017b). «Parque de la Amistad de Surco». Recuperado de: http:// www.surcoperu.com/turismo-surco-lima-peru/parque-de-la-amistadsurco.php

TAKANO, G., y J. ToKeshi (2007). Espacio público en la ciudad popular: reflexiones y experiencias desde el sur. Lima: Desco.

Talancha, E. (2013). Régimen legal de los parques ambientales en el Perú. Cuadernos de Investigación. Serie: Derecho Ambiental. Lima: Instituto Peruano de Derecho Ambiental y Patrimonio Cultural.

Watson, G. B. (2013). «The art of place making». In: Krause, L. Sustaining cities: Urban policies, practices and perceptions. Rutgers, pp 76-94. 